\title{
AfricArXiv
}

\section{COVID-19 Response in Nigeria: successes, challenges and ways forward}

Chinwe Lucia Ochu, Imam Wada Bello, Ndadilnasiya Endie Waziri, Umar Ahmad ${ }^{1}$

${ }^{1}$ SciComm Nigeria

Published on: Jun 29, 2020

DOI: $10.21428 / 3 b 2160 c d . d c 27 f b 4 c$

License: Creative Commons Attribution 4.0 International License (CC-BY 4.0). 


\section{Science Communication Hub Nigeria Presents:}

\section{COVID-19 Response in Nigeria: successes, challenges} and ways forward

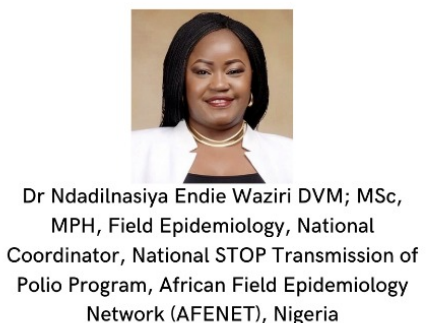

Saturday June 6, 2020 11AM WAT

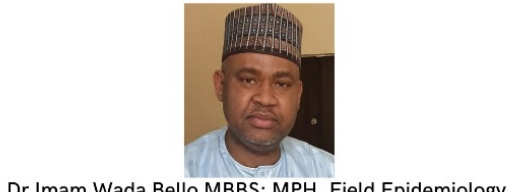

Dr Imam Wada Bello MBBS; MPH, Field Epidemiology, MWACP, Director Public Health \& Disease Control,

Ministry of Health Kano/Secretary Covid-19 STF Kano, Nigeria

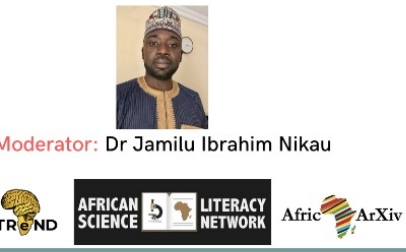

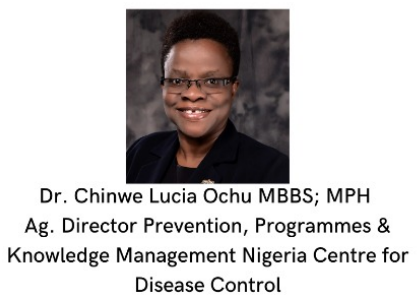

Streaming on

\section{$f_{\text {roun }}^{\text {rou }}$}

\#SciComNigeria \#COVID19Nigeria

Expert discussion with:

1. Dr Ndadilnasiya Endie Waziri, National Coordinator, National STOP Transmission of Polio Program, African Field Epidemiology Network (AFENET), Nigeria.

2. Dr Imam Wada Bello MBBS; MPH, Field Epidemiology, MWACP, Director Public Health \& Disease Control, Ministry of Health Kano/Secretary Covid-19 STF Kano, Nigeria.

3. Dr. Chinwe Lucia Ochu MBBS; MPH Ag. Director Prevention, Programmes \& Knowledge Management Nigeria Centre for Disease Control.

Visit the web version of this article to view interactive content. 